\title{
ANALISIS FAKTOR - FAKTOR YANG MEMPENGARUHI KETEPATAN WAKTU PENYAMPAIAN LAPORAN KEUANGAN DI DINAS TENAGA KERJA DAN TRANSMIGRASI (Studi Se-SUMATERA SELATAN)
}

\author{
Oleh: Ely Susanti \\ (UNIVERSITAS IBA PALEMBANG)
}

\begin{abstract}
Abstrak
Analisis Faktor - Faktor yang Mempengaruhi Ketepatan Waktu Penyampaian Laporan Keuangan di Dinas Tenaga Kerja Dan Transmigrasi (Studi Se-Sumatera Selatan), Effriyanti, SE, M.Si sebagai Ketua Pembimbing dan Pandriadi, SE, M.Si Sebagai Anggota pembimbing. Tujuan penelitian ini adalah Untuk mendapatkan bukti empiris bahwa latar bekang pendidikan, peraturan, perangkat pendukung dan aksesibilitas wilayah berpengaruh pada ketepatan waktu penyampaian laporan keuangan di Dinas Tenaga Kerja dan Transmigrasi Se-Sumatera Selatan. Hasil analisis menunjukkan bahwa nilai $F$ hitung sebesar 3,640 yang berarti $F$ hitung $(3,640)>F$ tabel $(2,61)$. Akan tetapi nilai koefisien determinan ( $R$ Square) atau pengaruh yang diberikan oleh variabel peraturan, latar belakang pendidikan, perangkat pendukung dan aksesibilitas wilayah hanya sebesar 0,272 atau 27,20\%, sedangkan sisanya sebesar 72,80\%. Ini menunjukan bahwa variabel estimasi atau faktor-faktor lain lebih mempengaruhi ketepatan waktu penyampaian laporan keuangan. Berdasarkan temuan tersbut maka dapat meningkatkan kualitas penyampaian laporan keuangan tepat pada waktun di Dinas Tenaga Kerja Dan Transmigrasi (Studi Se-Sumatera Selatan) dapat ditingkatkan dengan dukungan yang baik peraturan $\left(X_{1}\right)$, Latar Belakang Pendidikan $\left(X_{2}\right)$, Perangkat Pendukung $\left(X_{3}\right)$, dan aksesibilitas Wilayah $\left(X_{4}\right)$.
\end{abstract}

Kata Kunci: Peraturan, Latar Belakang Pendidikan, Perangkat Pendukung, Aksesibilitas Wilayah dan ketepatan waktu penyampaian laporan keuangan

\section{ANAL YSIS OF FACTORS THAT INFLUENCE THE TIMELINESS OF SUBMISSION OF THE FINANCIAL STATEMENTS IN THE MANAGEMENT OF LABOR AND TRANSMIGRATION (SOUTH SUMATERA STUDY)}

\begin{abstract}
Analysis of Factors Affecting the Timeliness of Submission of Financial Reports in the Department of Manpower and Transmigration (Studies in South Sumatra), Effriyanti, SE, M.Sc as Chairperson and Pandriadi, SE, M.Si As a Supervisor Member. The purpose of this study was to obtain empirical evidence that the background of education, regulation, supporting devices and regional accessibility affected the timeliness of the submission of financial reports in the South Sumatra Manpower and Transmigration Service. The results of the analysis show that the calculated $F$ value is
\end{abstract}


3,640 which means $F$ count (3,640)> F table (2,61). However, the determinant coefficient value ( $R$ Square) or the influence given by regulatory variables, educational background, supporting devices and regional accessibility is only 0.272 or $27.20 \%$, while the remaining is $72.80 \%$. This shows that estimation variables or other factors influence the timeliness of the submission of financial statements. Based on the findings, it can improve the quality of the delivery of financial statements in time at the Department of Manpower and Transmigration (South Sumatra Study) can be improved with good support regulations (X1), Educational Background (X2), Supporting Devices $(X 3)$, and Regional accessibility (X4).

Keywords: Regulation, Educational Background, Supporting Devices, Regional Accessibility and timeliness of financial report submission

\section{A. PENDAHULUAN}

\section{Latar Belakang}

Pemerintah daerah selaku pihak yang diberikan mandat oleh rakyat untuk mengelola dan menyelenggarakan pemerintahan di daerah harus mempertanggung jawabkan kinerjanya kepada rakyat. Transparansi yaitu keterbukaan pemerintah dalam membuat kebijakan-kebijakan keuangan daerah sehingga dapat diketahui dan diawasi oleh DPRD dan Masyarakat (Mardiasmo, 2002).

$$
\text { Untuk menyelenggarakan }
$$
akuntansi pemerintahan daerah kepala daerah menetapkan sistem akuntansi pemerintah daerah dengan mengacu pada peraturan daerah tentang pokokpokok pengelolaan keuangan daerah. Dalam sistem akuntansi pemerintahan ditetapkan entitas pelaporan dan entitas akuntansi yang menyelenggarakan sistem akuntansi pemerintahan daerah.
Entitas pelaporan dan entitas akuntansi tersebut menurut ketentuan peraturan perundang-undangan wajib menyampaikan laporan pertanggungjawaban berupa laporan keuangan pada akhir periode dan untuk mengontrol perbulannya dilakukan laporan bulanan dan laporan triwulan. Ketepatan waktu pelaporan keuangan bisa berpengaruh pada nilai laporan keuangan tersebut (Kenley dan Stubus, 1972 dalam Ukago, 2005).

Dalam penyampaian laporan bulanan selambat-lambatnya 7 (tujuh) hari kerja setelah bulan bersangkutan berakhir sebagai bahan rekonsiliasi data dan pengawasan atas ketaatan terhadap peraturan perundang-undangan. Adapun untuk laporan triwulan pertama 31 Maret, akhir triwulan kedua adalah 30 Juni, akhir triwulann ketiga adalah 30 September dan akhir triwulan keempat adalah 31 Desember. Terdapat 
keterlambatan penyampaian laporan keuangan di Kabupaten Lahat, Kabupaten Empat Lawang dan Kota Lubuk Linggau.

Dinas Tenaga Kerja dan Transmigrasi Se-Sumatera Selatan adalah instansi pemerintah yang bergerak dibidang pemberdayaan masyarakat desa tertinggal dan transmigrasi masyarakat dari luar daerah Sumatera Selatan. Dalam usaha pengelolaan keuangan daerah instansi ini juga melaporkan laporan keuangan yang telah dikelola untuk masa pencatatan per 31 Desember. Laporan pertanggungjawaban penggunaan keuangan tersebut nantinya akan diaudit terlebih dahulu oleh badan audit pemerintah sebelum di publikasikan ke masyarakat. Peraturan perundangundangan dapat mengatur bahwa laporan keuangan harus diterbitkan pemerintah pada waktu tertentu (BPK, 2008) . Apabila pemeriksa mengetahui bahwa laporan keuangan pemerintah tersebut tidak dapat diterbitkan tepat waktu, pemeriksa harus mengungkapkannya dalam laporan hasil pemeriksa atas laporan keuangan.

Ada beberapa faktor yang mempengaruhi ketepatan waktu penyampaian laporan keuangan berupa peraturan, latar belakang pendidikan, perangkat pendukung dan aksesibilitas wilayah yang akan diuji dalam penelitian ini. Berdasarkan uraian tersebut, maka penelitian ini akan difokuskan untuk mengetahui faktorfaktor yang mempengaruhi ketepatan waktu dalam penyusunan laporan keuangan. Oleh karena itu penelitian ini mengambil judul : "Analisis Faktor Faktor yang Mempengaruhi Ketepatan Waktu Penyampaian Laporan Keuangan di Dinas Tenaga Kerja Dan Transmigrasi (Studi Se-Sumatera Selatan)".

\section{Rumusan Masalah}

Berdasarkan latar belakang masalah, maka dirumuskan permasalahan, "Bagaimana pengaruh latar belakang pendidikan, peraturan, perangkat pendukung dan aksesibilitas wilayah terhadap ketepatan waktu penyampaian laporan keuangan di Dinas Tenaga Kerja dan Transmigrasi Se-Sumatera Selatan".

\section{Tujuan Penulisan}

Adapun tujuan penulisan Aktikel ini adalah: Untuk mendapatkan bukti empiris bahwa latar bekang pendidikan, peraturan, perangkat pendukung dan 
aksesibilitas wilayah berpengaruh pada ketepatan waktu penyampaian laporan keuangan di Dinas Tenaga Kerja dan Transmigrasi Se-Sumatera Selatan.

\section{B. METODE}

Pada penelitian ini yang menjadi objek utama penelitian adalah bendahara pegawai pada kantor Dinas Tenaga Kerja dan Transmigrasi SeSumatera Selatan pada unit kerja penyusunan laporan keuangan pada setiap substansi kerja. Unit kerja pada Dinas Tenaga Kerja dan Transmigrasi Se-Sumatera Selatan terdiri dari 15 Provinsi/ Kabupaten/ Kota kerja. Dimana terdapat sejumlah 44 orang bendaharawan yang kesemuanya menjadi sampel dalam penelitian ini.

Tehnik pengumpulan data pada penelitian ini menggunakan : Penelitian Lapangan (Field Research), Penelitian Kepustakaan (Library Research), dengan prosedur pengumpulan data menggunakan wawancara dan kuesioner yang disebarkan kepada 44 orang responden.

$$
\text { Adapun Variabel yang }
$$
dianalisis/diujicobakan pada penelitian ini yang terdiri dari dua variable utama yaitu variable dependen (Y) yaitu ketepatan waktu penyampaian laporan keuangan dan variable independen (X) factor-faktor yang mempengaruhi ketepatan waktu penyampaian laporan keuangan yang terdiri dari $\left(\mathrm{X}_{1}\right)$ Peraturan, $\left(\mathrm{X}_{2}\right) \quad$ Latar Belakang Pendidikan, $\left(\mathrm{X}_{3}\right)$ Perangkat Pendukung dan $\left(\mathrm{X}_{4}\right)$ Aksesibilitas Wilayah. Keempat variable independen (X) akan diujicobakan baik secara parsial maupun secara simultan terhadap variable dependen (Y).

Untuk mengetahui pengaruh variable independen (X) terhadap variable (Y) peneliti menggunakan perhitungan statistic penelitian dengan menggunakan program SPSS for Windows versi 21 untuk menguji data awal, uji hipotesis penelitian, uji parsial dan uji simultan masing-masing variable yang diteliti.

\section{HASIL DAN PEMBAHASAN}

Hasil Peengujian statistik dengan menggunakan program SPSS for Windows versi 21, diketahui nilai statistic pengujian awal data sebagai berikut :

- Uji Validitas, diketahui bahwa seluruh instrument dapat dikatakan valid dimana nilai $\mathbf{r}$ hitung $0,310-0,814>\mathbf{r}$ tabel 0,204 . 
- Uji Reliabilitas, diketahui bahwa seluruh instrument dapat dikatakan reliabel dimana nilai r hitung $0,318-0,410>\mathbf{r}$ tabl 0,304 .

- UJi Heterokedastisitas, diketahui nilai $\left(\mathrm{X}_{1}\right)$ sebesar 0,054 , variabel $\left(\mathrm{X}_{2}\right)$ sebesar 0,675, variabel $\left(\mathrm{X}_{3}\right)$ sebesar 0,224 dan variabel $\left(\mathrm{X}_{4}\right)$ adalah sebesar 0,019 maka dapat dikatakan bahwa seluruh variabel independen dalam penelitian ini bebas dari gejala heterokedastisitas.

- Uji Mutikolinieritas, diketahui nilai $\left(\mathrm{X}_{1}\right)$ sebesar 1,244, $\left(\mathrm{X}_{2}\right)$ sebesar 1,352, variabel $\left(\mathrm{X}_{3}\right)$ sebesar 1,149 dan variabel $\left(\mathrm{X}_{4}\right)$ adalah sebesar 1,106. Hal ini menunjukan semua nilai VIF dari setiap variabel berada dibawah nilai 10 , dengan demikian semua variabel dalam penelitian ini bebas dari penyakit multikolinearitas.

- Uji normalitas, dimana $\left(\mathrm{X}_{1}\right)$ sebesar 0,272 , variabel $\left(\mathrm{X}_{2}\right)$ sebesar 0,244, variabel $\left(\mathrm{X}_{3}\right)$ sebesar 1,147, variabel $\left(\mathrm{X}_{4}\right)$ adalah sebesar 0,711 lebih besar dari tingkat signifikan 0,05 dan variable ketepatan waktu (Y) adalah sebesar 0,065 dengan demikian dapat ditarik kesimpulan bahwa residual terdistribusi secara normal.

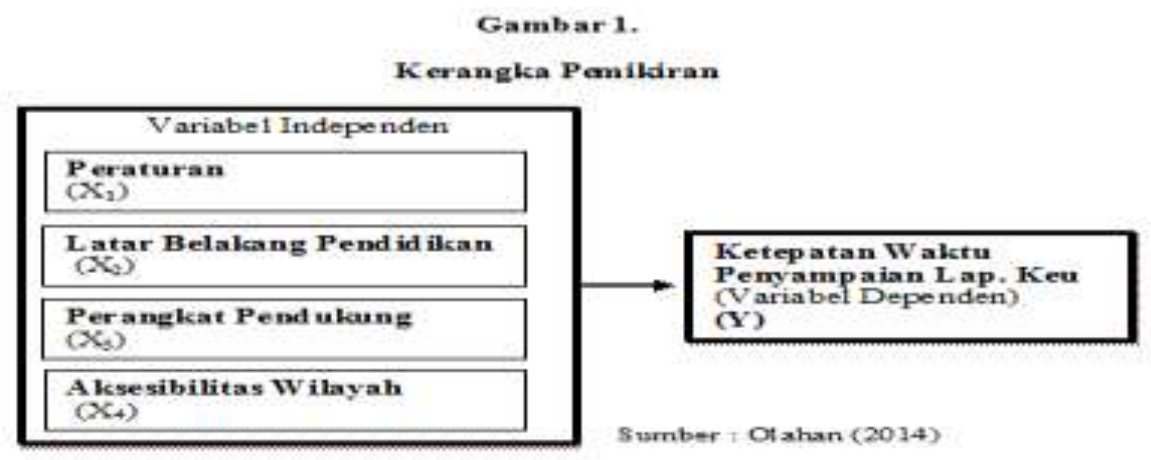

Hasil pengujian hipotesis wilayah memiliki nilai $\mathrm{F}$ hitung sebesar statistic dengan menggunakan program SPSS for Windows versi 21, diketahui 3,640 yang lebih besar dari $\mathrm{F}$ tabel sebesar 2,61 $(\mathrm{F}$ tabel $=.[\mathrm{n}-\mathrm{k}-1]=2,61)$. hasil pengujian statistic secara simultan, Kemudian jika dilihat dari nilai dapat diketahui bahwa variabel probabilitas yaitu sebesar $0,002<0,05$ peraturan, latara belakang pendidikan, (tingkat signifikansi 5\%). Hal ini perangkat pendukung, dan aksesibilitas menunjukan bahwa semua variabel 
independen secara simultan memiliki pengaruh yang signifikan terhadap ketepatan waktu penyampaian laporan keuangan. Atau dengan kata lain variabel peraturan, latara belakang pendidikan, perangkat pendukung, dan aksesibilitas wilayah secara simultan berpengaruh signifikan terhadap ketepatan waktu penyampaian laporan keuangan. Dengan demikian dapat ditarik kesimpulan hipotesis dalam penelitian ini diterima. Terdapat pengaruh yang signifikan Peraturan, Latar Belakang Pendidikan, Perangkat Pendukung dan Aksesibilitas Wilayah tidak berpengaruh secara simultan terhadap ketepatan waktu penyampaian laporan keuangan.

Setelah melalui beberapa pengujian, maka akan terbentuk suatu model matematis yang digunakan untuk menjelaskan suatu output dari penelitian. Persamaan regresi linier berganda dalam penelitian ini adalah sebagai berikut:

Hasil pengujian koefisien determinasi, diketahui hasil pengujian menunjukan bahwa variasi ketepatan waktu penyampaian laporan keuangan dijelaskan oleh variabel peraturan, latar belakang pendidikan, perangkat pendukung dan aksesibilitas wilayah dengan nilai $\mathrm{R}$ Square sebesar 0,272 atau $27,20 \%$, sedangkan sisanya sebesar $72,80 \%$ dijelaskan oleh variabel atau faktor lain yang tidak dianalisis dalam penelitian ini.

Setelah melakukan beberapa tahap pengujian pada variabel peraturan, latar belakang pendidikan, perangkat pendukung dan aksesibilitas wilayah terhadap ketepatan waktu penyampaian laporan keuangan, hasil pengujian hipotesis (uji F) menunjukan bahwa variabel peraturan, latar belakang pendidikan, perangkat pendukung dan aksesibilitas wilayah secara simultan berpengaruh signifikan terhadap kualitas bahan bukti audit. Hasil menunjukan nilai $\mathrm{F}$ hitung sebesar 3,640 yang berarti $\mathrm{F}$ hitung $(3,640)>\mathrm{F}$ tabel $(2,61)$. Akan tetapi nilai koefisien determinan ( $\mathrm{R}$ Square) atau pengaruh yang diberikan oleh variabel peraturan, latar belakang pendidikan, perangkat pendukung dan aksesibilitas wilayah hanya sebesar 0,272 atau 27,20\%, sedangkan sisanya sebesar $72,80 \%$. Ini menunjukan bahwa variabel estimasi atau faktor-faktor lain lebih mempengaruhi ketepatan waktu penyampaian laporan keuangan. Hal ini sesuai dengan acuan AIA 
D. KESIMPULAN DAN SARAN

$>$ KESIMPULAN

Setelah melewati beberapa tahapan akhirnya peneliti dapat menarik kesimpulan sebagai berikut:

1. Hasil penelitian menunjukan bahwa variabel peraturan, latar belakang pendidikan, perangkat pendukung dan aksesibilitas wilayah secara simultan berpengaruh signifikan terhadap kualitas bahan bukti audit, dengan nilai $\mathrm{F}$ hitung sebesar 3,640 yang lebih besar dari $F$ tabel sebesar 2,61 (F tabel $=2,61)$. Kemudian dilihat dari nilai probabilitas yaitu sebesar $0,002<$ 0,05 (tingkat signifikansi 5\%). Maka disimpulkan Ho ditolak dan H1 diterima.

2. Hasil penelitian menunjukkan bahwa ketepatan waktu penyampaian laporan keuangan sebesar $27,20 \%$ dapat dijelaskan oleh variabel peraturan, latar belakang pendidikan, perangkat pendukung dan aksesibilitas wilayah sisanya sebesar $72,80 \%$ dijelaskan oleh variabel lain yang tidak dianalisis dalam penelitian ini.

3. Berdasarkan data responden yang diperoleh, menunjukan bahwa sampai pada saat ini para bendaharawan yang bekerja pada Kantor Dinas Tenaga Kerja dan Transmigrasi Se-Sumatera Selatan masih didominasi oleh lulusan pendidikan program studi akuntansi, hal ini mungkin disebabkan perundang-undangan mengenai profesi bendaharawan yang baru disahkan tahun 2011 lalu dan masih kurangnya minat lulusan pendidikan program studi lain yang ingin menjadi seorang bendaharawan.

\section{$>$ SARAN}

1. Bagi Peneliti Selanjutnya

- Disarankan untuk mencari objek atau responden penelitian lain selain bendaharawan pada Kantor Dinas Tenaga Kerja dan Transmigrasi Se-Sumatera Selatan, karena berdasarkan pengalaman peneliti sendiri terdapat kendala saat mengumpulkan data di lapangan.

- Diharapkan peneliti selanjutkan agar mengikutsertakan bendaharawan pada instansi lain yang berwilayah di Provinsi 
Sumsel, agar lingkup penelitian lebih luas.

- Untuk hasil yang lebih baik disarankan para peneliti selanjutnya menggunakan waktu yang tepat untuk menyebar kuesioner agar meminimalisir kuesioner yang tidak kembali.

- Menggunakan sampel atau responden penelitian yang lebih banyak.

- Menambah variabel lain selain variabel yang telah digunakan oleh peneliti, dikarenakan hasil dari penelitian ini memiliki nilai koefisien determinan yang rendah.

- Sebaiknya menggunakan metode penelitian atau teknik analisis yang berbeda agar hasil yang didapat lebih bervariasi.

- Agar hasil penelitian lebih maksimal gunakan open kuesioner agar peneliti mendapatkan informasi mengenai kendala-kendala responden ketika melakukan proses auditing terutama saat mengumpulkan bahan bukti audit.

2. Bagi para bendaharawan
Diharapkan meningkatkan kerjasamanya dengan pihak-pihak yang ingin meneliti di Kantor Dinas Tenaga Kerja dan Transmigrasi SeSumatera Selatan.

\section{DAFTAR PUSTAKA}

Peraturan Direktur Jenderal Perbendaharaan Nomor Per19/PB/2008 tentang Pengenaan Sanksi atas Keterlambatan Penyampaian Laporan Keuangan Sesuai dengan Peraturan Menteri Keuangan No. 171/PMK.05/2007 tentang Sistem Akuntansi dan Pelaporan Keuangan Pemerintah Pusat.

Binsar Antonius, (2013). Faktor-Faktor yang Mempengaruhi Ketepatan Waktu Penyampaian Laporan Keuangan

Kementrian Keuangan Negara/Lembaga Tingkat Satuan Kerja UAKAP. Malang: Universitas Brawijaya. Ikatan Akuntan Indonesia, (2007). Standar Akuntansi Keuangan, buku I dan II. Jakarta: Salemba Emapat

Santoso Iman. 2009. Akuntansi Keuangan Menengah (Intermediate Accounting). Bandung : Refika Aditama. 
Sarwono, Jonathan dan Herlina

Budiono. 2012. Statistik Terapan

: Aplikasi Untuk Riset Skripsi,

Tesis dan Disertasi

(Menggunakan SPSS,AMOS

dan Excel) Jakarta : Exel Media

Komputindo.

Sudjana. 2002. Metode

Statistik.Bandung: Pt. Tarsito

Sugiyono, 2010, Metode Penelitian

Kuantitatif Kualitatif dan R\&D,

Bandung, Alfabeta 